\title{
INFLUÊNCIA DA VIBRAÇÃO GERADA PELO TRÁFEGO FERROVIÁRIO NO MEIO URBANO
}

\section{INFLUENCE OF VBRATION GENERATED BY RAILWAY TRAFAC IN URBAN AREAS}

\section{Luiz Antonio Perrone Ferreira de Brito ${ }^{1}$}

Universidade de Taubaté, Programa de Mestrado em Gestão e Desenvolvimento Regional, Taubaté, SP, Brasil, labrito@bighost.com.br

\section{Quésia Kamimura²}

Universidade de Taubaté, Programa de Mestrado em Gestão e Desenvolvimento Regional, Taubaté, SP, Brasil, qkamimura@gmail.com

\section{Ademir Pereira dos Santos ${ }^{3}$}

Universidade de Taubaté, Programa de Mestrado em Gestão e Desenvolvimento Regional, Taubaté, SP, Brasil, ademir@me.com

\section{Resumo}

A vibração ambiental é um efeito que nem sempre é considerado nas análises urbanas e nos projetos de engenharia em geral. Para quantificação da energia vibratória é utilizado o pico de velocidade da partícula (PVP). A PVP é obtida pela da somatória do vetor aceleração nos três eixos ortogonais que é integrado pelo medidor resultando na velocidade. No Brasil não há uma normalização específica para avaliar a vibração ambiental, sendo utilizados padrões internacionais, que nem sempre se adaptam a realidade nacional. O objetivo deste trabalho é avaliar a influência da vibração gerada pelo tráfego ferroviário no meio urbano por meio de medições da PVP e verificar se os critérios internacionais são válidos para as condições construtivas no Brasil. No local selecionado foram realizadas medidas á várias distâncias sendo avaliados os critérios de incomodidade e danos estruturais. Verificou-se que mesmo com PVPs abaixo dos critérios, há claros danos nas edificações o que indica que este assunto deve ser aprofundado para se criar parâmetros que atendam a realidade brasileira.

Palavras-chave: Vibração. Ambiente. Urbanismo.

\begin{abstract}
Environmental vibration is an effect not always regarded as relevant in urban studies and in engineering projects. In order to quantify vibratory energy, it is common to use the peak particle velocity (PPV) parameter. PPV is obtained by the acceleration vector sum in the three orthogonal axes integrated by a measuring device, resulting in the final velocity value. However, there is no specific national legal norm to regulate environmental structural vibration, thence; international standards are in place instead. Nonetheless, these standards do not always conform to the national expectations. The objective of this study is to assess the influence of railway traffic vibration on urban environments by means of PPV measurements, and to verify whether the international standards are valid for the structural conditions found in the analyzed site. In the chosen study site, measurements were performed over pre-determined distances in order to evaluate for structural damage and locality inconvenience. It was verified that even though the PPVs values were below a criterion threshold, there were clear building damages. This is an indication that this subject must be further investigated for the development of parameters that better meet the Brazilian needs.
\end{abstract}

Keywords: Vibration. Environment. Urbanism.

How to cite this article:

BRITO, Luiz Antonio Perrone Ferreira de; KAMIMURA, Quésia. SANTOS, Ademir Pereira dos. Influência da vibração gerada pelo tráfego ferroviário no meio urbano. PARC Pesquisa em Arquitetura e Construção, Campinas, v. 5, n. 2, p. 31-39, jul./dez. 2015 


\section{Introdução}

A vibração ambiental é um efeito que nem sempre é considerado nas análises urbanas e nos projetos de engenharia em geral, principalmente nos edificios residenciais e comerciais. A transmissão das ondas vibratórias pelo solo depende de sua composição e estratificação e do tipo de fonte geradora. Para quantificação da energia vibratória é utilizado o pico de velocidade da partícula (PVP). A PVP é obtida pela da somatória do vetor aceleração nos três eixos ortogonais que é integrado pelo medidor resultando na velocidade. Os efeitos da vibração no meio urbano podem ser classificados pela incomodidade às pessoas ou pelos danos estruturais às edificações. A aproximação de edificações de linhas férreas é uma situação recorrente em todo o Brasil, o que é problemático, já que aproxima a fonte de vibração do receptor, reduzindo a distância percorrida pela onda, que é a principal forma de atenuação da energia vibratória. No Brasil não há uma normalização específica para avaliar esta situação sendo utilizado, portanto padrões internacionais, que nem sempre se adaptam a realidade nacional. O objetivo deste trabalho é avaliar a influência da vibração gerada pelo tráfego ferroviário no meio urbano por meio de medições do pico da velocidade da partícula (PVP) e verificar se os critérios internacionais são válidos para as condições construtivas encontradas no local analisado. No local selecionado foram realizadas medidas á várias distâncias sendo avaliados os critérios de incomodidade e danos estruturais. Verificou-se que mesmo com PVPs abaixo dos critérios há claros danos nas edificações o que indica que este assunto deve ser aprofundado para se criar parâmetros que atendam a realidade brasileira.

\section{Revisão da Literatura}

A vibração ambiental é um efeito que nem sempre é considerado nas análises urbanas e nos projetos de engenharia em geral. A ausência ou pequena frequência de fenômenos naturais de grande intensidade no Brasil, capazes de excitar uma estrutura com modos vibratórios, como terremotos e furacões, nos dá a sensação que a energia vibratória é inofensiva para os usuários das edificações em geral. Nos prédios industriaís, pontes, ginásios e estádios, salões de festas e outros locais onde os esforços oriundos dos carregamentos dinâmicos são significativos em relação aos esforços provenientes dos carregamentos estáticos, o dimensionamento estrutural atende a critérios de amortecimento para evitar danos estruturais. Mas este cuidado nem sempre é considerado para as edificações de uso corrente da população como os edificios residenciais e comerciais que podem estar expostos a energia vibratória gerado pelo tráfego ferroviário e rodoviário.

A transmissão das ondas vibratórias pelo solo depende de sua composição e extratificaçao e tipo de fonte geradora. Em geral as ondas vibratórias são geradas no solo na forma de ondas decompressão ou cisalhamento (como velocidade em apenas uma direção), quando próximas do ponto de geração da vibração, que se transformam em ondas tipo Rayleigh (com velocidade em duas direções) quando refletidas pela superfície do solo (ATTEWELL; SELBY; O'DONNELL, 1992). A velocidade de propagação da onda sonora no solo é inversamente a proporcional à energia vibratória induzida nas edificações. Nos solos mais rígidos (como os argilosos coesivos) a propagação da energia vibratória ocorre em maiores velocidades, sendo que a tensão gerada nas fundações, e consequentemente a vibração induzida, são menores. O inverso ocorre nos solos menos rígidos como os arenosos (BS 7385-2, 1993). A variável utilizada para quantificação da vibração em uma superfície é a velocidade da partícula, pois tem conotação de tensão, sendo esta relacionada com os principais danos estruturais. A aceleração está relacionada com a deformação sendo adotada por sismologistas em análises de terremotos (ATTEWELL; SELBY; UROMEIHY, 1989). Para quantificação da energia vibratória é utilizado, portanto o pico de velocidade da partícula, PVP, sendo considerado o vetor resultante da somatória obtida dos eixos, X, Y e Z (ATTEWELL; SELBY; O’DONNELL, 1992).

As edificações que possuem estrutura formal em aço ou concreto armado tendem a receber melhor os efeitos da vibração, desde que projetadas para tal. Em contrapartida, as construções antigas e patrimônios históricos, edificados com materiais menos resistentes, como a alvenaria de tijolos de barro, queimados em fornos ou não, e em algumas situações mal conservadas, taipa ou madeira, podem sofrer desde rachaduras menores até danos estruturais irreversíveis quando expostas a elevados níveis de vibração (BRITO, 2011). As fundações pesadas previnem a deformação devido à vibração induzida nas paredes sendo que as trincas são usuais em edificações de estruturas leves. No caso de estrutura rígida e apoiada em um solo de baixo amortecimento, o deslocamento nas paredes da edificação é praticamente nulo devido à resposta de corpo rígido da edificação. No caso de estruturas flexíveis apoiadas em solos rígidos, os deslocamentos nas fundações, são desprezíveis, mas as paredes deformam, acompanhando a movimentação do solo, o que resulta em trincas (FRANÇOIS et al., 2007). Caso a frequência de ressonância da estrutura da edificação seja similar a frequência de propagação da onda vibratória 
haverá amplificação do deslocamento de solo/fundação ocasionando um impacto indesejado segundo a BS 73851 (BRITISH STANDARD, 1990). Outro efeito importante gerado pela vibração é o adensamento do solo, principalmente os arenosos, que podem gerar recalques diferenciais podendo haver o rompimento da estrutura (HUNAIDI, 2000).

O tráfego ferroviário e rodoviário é uma importante fonte de vibração no meio urbano. Existe uma tendência de utilização de parte das faixas de domínio de rodovias e ferrovias para construção de novas edificações além da redução dos recuos obrigatórios nos códigos de obras municipais, o que aproxima a fonte do receptor (BRITO, 2013), sendo esta uma situação recorrente em todo o território nacional. Além destas, também existem ouras fontes significativas de vibração, como as ligadas a construção civil, descritas em Brito (2014)

O nível de vibração gerada pelo tráfego rodoviário e ferroviário depende das condições da via ou dos trilhos, do peso do veículo, da sua velocidade e do o tipo do solo (HUNAIDI, 2000). No caso do tráfego rodoviário os pavimentos irregulares, como os prismáticos (paralelepípedos) a base de rochas ígneas (granitos), são os que geram mais energia vibratória, sendo que a pavimentação asfáltica de boa qualidade é uma medida mitigadora eficiente segundo a BS 5228-2 (BRITISH STANDARD, 2009). No caso do tráfego ferroviário a velocidade e carga transportada são os fatores que mais influenciam na vibração gerada, podendo induzir PVP de até $100 \mathrm{~mm} / \mathrm{s}$ no solo próximo ao lastro de pedra (KIM; LEE, 2000).

Segundo BACGI et al. (2003) a principal referência internacional para que se estude os efeitos da energia vibratória em estruturas é dada pela norma DIN 4150-3, Vibration in buildings, effect in structures (DEUTSCHES INSTITUT FUR NORMUNG, 1999). Esta separa as edificações em três categorias de análise, baseado nas tipologias estruturais, e as velocidades a que podem estar expostas, conforme apresentado no Tabela 1. Os critérios apresentados na Tabela 1 se referem a valores globais de PVP. A DIN 4150-3 (DEUTSCHES INSTITUT FUR NORMUNG, 1999) apresenta também critérios para bandas de frequência de 1 a $10 \mathrm{~Hz}$, de 10 a $50 \mathrm{~Hz}$ e de 50 a $100 \mathrm{~Hz}$.

Os danos estruturais nas edificações podem ser classificados como cosméticos, com o aparecimento de pequenas fissuras (da espessura de um fio de cabelo, por exemplo) no reboco ou acabamento em gesso das paredes; de pequena monta, com o aparecimento de trincas (ou evolução de uma fissura para trinca) e queda do revestimento de reboco ou gesso; e de grande monta, com trincas estruturais em pilares, vigas e lajes (ISO 4866) (INTERNATIONAL ORGANIZATION FOR STANDARDIZATION, 2010).

Tabela 1 - Limites de Pico de Velocidade da Partícula (PVP) em (mm/s) para integridade estrutural

\begin{tabular}{lc}
\multicolumn{1}{c}{ Tipos de Edificação } & $\begin{array}{c}\text { PVP } \\
\text { (mm/s) }\end{array}$ \\
\hline $\begin{array}{l}\text { Categoria 1, edificações de concreto armado e de } \\
\text { madeira em boas condições }\end{array}$ & 40 \\
\hline Categoria 2, edificações de alvenaria em boas condições & 15 \\
\hline $\begin{array}{l}\text { Categoria 3, edificações de alvenaria em más condições } \\
\text { de conservação e edificações consideradas de patrimônio } \\
\text { histórico }\end{array}$ & 8 \\
\hline \begin{tabular}{l} 
Fonte: DIN 4150-3 (DEUTSCHES INSTITUT FUR NORMUNG,1999) \\
\hline
\end{tabular}
\end{tabular}

Outro efeito da vibração é a incomodidade gerada aos ocupantes de uma edificação. Este efeito pode se intolerável devido à sensação física de movimento que interfere em algumas atividades como o sono, conversação devido à vibração de janelas e movimentação de objetos, além do receio de danos à edificação segundo a BS 5228-2(BRITISH STANDARD, 2009). Os limites de incomodidade,em valores globais,para os ocupantes de uma edificação são dados pelaISO 2631-2conforme apresentado na Tabela 2. Assim como a DIN 4150-3 (DEUTSCHES INSTITUT FUR NORMUNG,1999), a ISO 2631 (INTERNATIONAL ORGANIZATION FOR STANDARDIZATION, 1997) também apresenta critérios por banda de frequência.

Tabela 2 - Limites de Pico de Velocidade da Partícula (PVP) em (mm/s)para limites de incomodidade

\begin{tabular}{ccc}
\hline Tipos de Edificação & $\begin{array}{c}\text { DIURNO } \\
\text { PVP }(\mathbf{m m} / \mathbf{s})\end{array}$ & $\begin{array}{c}\text { NOTURNO } \\
\text { PVP }(\mathbf{m m} / \mathbf{s})\end{array}$ \\
\hline Hospitais & 0,10 & 0,10 \\
\hline Residências & 0,40 & 0,14 \\
\hline Escritórios & 0,40 & 0,40 \\
\hline Oficinas & 0,80 & 0,80
\end{tabular}

Fonte: ISO 2631-2 (INTERNATIONAL ORGANIZATION FOR STANDARDIZATION,1997)

No Brasil não há uma normalização específica para o assunto sendo que a que mais se aproxima é a NBR 9653 (ASSOCIAÇÃO BRASILEIRA DE NORMAS TÉCNICAS, 2005) quenão aborda o tema de maneira satisfatória, no caso de vibração induzida pelo tráfego ferroviário e de veículos, sendo indicada para situações de detonação e desmonte de rochas. Outra referência é a CETESB DD 215 (COMPANHIA DE TECNOLOGIA DE SANEAMENTO AMBIENTAL, 2007), mas esta se restringe ao Estado de São Paulo e não distingue os tipos de estrutura analisadas.

Para uma avaliação ambiental, a forma do decaimento da energia sonora é um importante fator a ser considerado. A literatura apresenta vários trabalhos de modelagem 
relacionados a esse tema que são apresentados e discutidos em Brito (2014). Em geral, a precisão dos resultados esbarra na qualidade dos dados de entrada, como o amortecimento do solo, por exemplo, que impede que simulações sejam realizadas com precisão, mesmo que se utilizem técnicas avançadas como o método de elementos finitos (GUPTA; DEGRANDE; LOMBAERT, 2009). Kin e Lee (2000) apresentaram uma proposta de modelagem de acordo com a Equação 1. Esta modelagem é baseada no pré-conhecimento da PVP (w1) a uma dada distância (r1), de maneira que seja possível calcular a PVP (w2) em uma distância (r2). O fator $\mathrm{n}$ se refere ao tipo de onda que a fonte gera no solo e o fator é referente ao tipo de solo. Estes podem ser obtidos em Athanasopoulos e Pelekis (2000).

$$
w_{2}=w_{1}\left(\frac{r_{1}}{r_{2}}\right)^{n} e^{-\alpha\left(r_{2}-r_{1}\right)}
$$

(Eq. 1)

\section{Método}

O local selecionado para as medições foi a linha férrea da Estrada de Ferro Central do Brasil que atravessa o centro urbano da cidade de Taubaté localizada na Região Metropolitana do Vale do Paraíba, no Cone Leste do Estado de São Paulo.

O leito da ferrovia é utilizado atualmente apenas para transporte de carga (minério, aço e cimento primordialmente). O peso médio de cada vagão é de 120 a 170 toneladas e a composição trafega a uma velocidade de $40 \mathrm{~km} / \mathrm{h}$ no local de medição.

As edificações que tiveram os efeitos da vibração aferidos pertencem a Vila Edmundo que possui edificações localizadas a partir de $5 \mathrm{~m}$ de distância do leito da ferrovia como é possível observar nas Figuras 1 e 2. Devido à proximidade da linha férrea e a construção de um viaduto na década de 1970 houve a desvalorização imobiliária deste trecho. Desta forma, as edificações são praticamente as mesmas das primeiras décadas do século XX, estando expostas ao efeito da vibração por todo esse período. Esta configuração urbana é recorrente em todo território nacional (edificações antigas construídas próximas à linha férrea) sendo os resultados obtidos neste trabalho são representativos para esta condição.A rua de acesso ao local de medição não tem saída, o que limita o tráfego rodoviário, e consequentemente a interferência nos resultados.

O equipamento utilizado para as medições foi um HVM100, marca Larson Davis, acoplado a um acelerômetro triaxial (capaz de fazer a leitura nos 3 eixos simultaneamente) DYTRAM modelo 3233AT com cerca de $980 \mathrm{mV} / \mathrm{g}$ de sensibilidade, sendo todos calibrados por laboratórios pertencentes a Rede Brasileira de Calibração do INMETRO. O acelerômetro obtém a aceleração no local de medição sendo que o sinal é integrado pelo equipamento para que seja obtida a velocidade, neste caso o pico de velocidade da partícula (PVP). O software BLAZE foi utilizado para tratamento dos dados. A banda de frequência de análise do equipamento é de 0,4 a $100 \mathrm{~Hz}$.

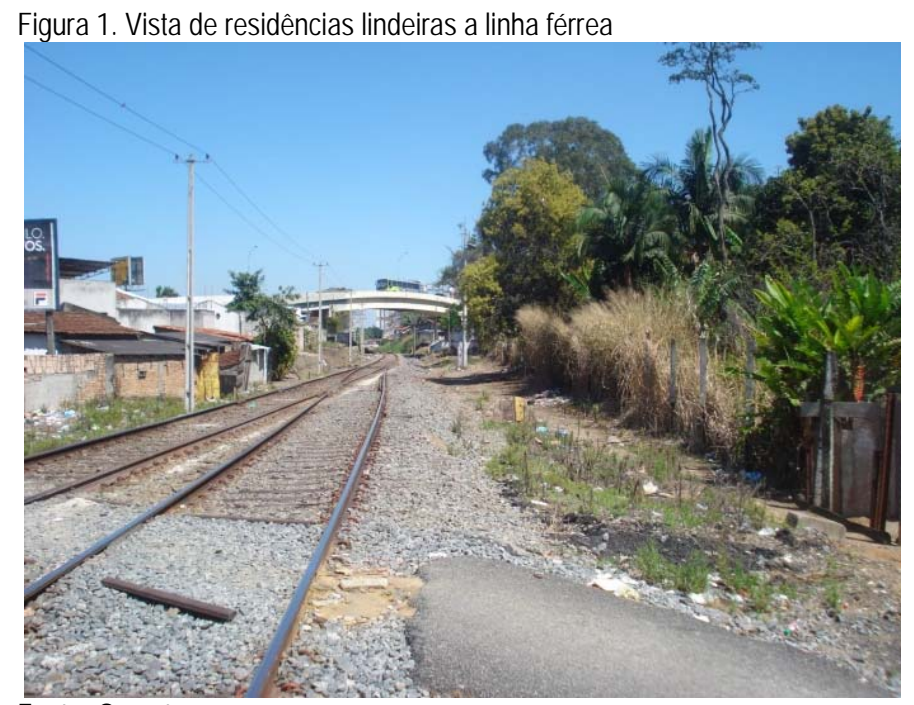

Fonte: Os autores

Figura 2.Vista de residências lindeiras à linha férrea

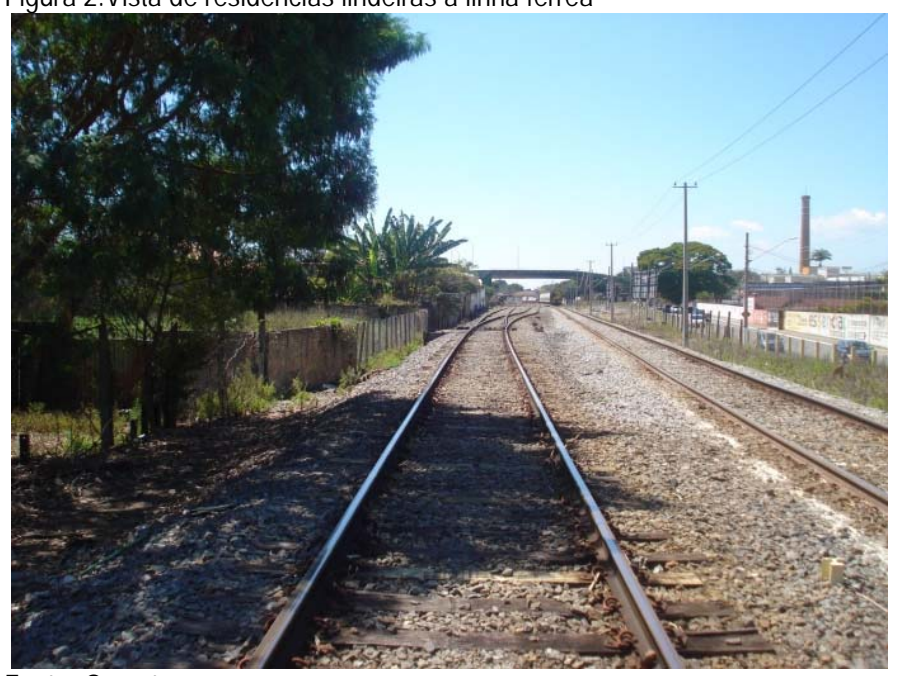

Fonte: Os autores

Os critérios normalizados adotados para comparação com os resultados obtidos foram os de valores globais. Esta é uma possibilidade facultada tanto pela DIN 4150-3 (DEUTSCHES INSTITUT FUR NORMUNG, 1999) quanto pela ISO 2631 (INTERNATIONAL ORGANIZATION FOR STANDARDIZATION, 1997), e atende o objetivo de uma avaliação ambiental. Mas, deve-se também considerar, que caso o objetivo da análise seja avaliar o comportamento estrutural de uma edificação, as medidas em bandas de frequência são fundamentais. 
Para coleta de dados o acelerômetro foi acoplado a um $P O D$ metálico por meio de um parafuso de modo que este transmitisse os deslocamentos ao equipamento. $\mathrm{O}$ POD possui apenas três apoios para que se ajuste ao chão, sem folgas. Os dados foram obtidos nos eixos $\mathrm{X}$ (perpendicular a fonte), Y (paralelo a fonte) e Z (perpendicular ao plano formado pelos eixos $\mathrm{X}$ e $\mathrm{Y}$ ) e calculado o valor resultante final pelo software. O tempo de coleta de dados variou de acordo com o tempo de passagem das composições, sendo que o equipamento armazena uma medida por segundo. A PVP considerada é o valor de pico obtido dentro do período de medição

Para que fosse possível a avaliação da influência do tráfego ferroviário no meio urbano foram efetuadas medidas da PVP em duas situações.

$\mathrm{Na}$ primeira avaliação o pod metálico foi apoiado no pavimento asfáltico ou de concreto, Figura 3, com o fim de avaliar a incomodidade aos residentes lindeiros à linha, já que é neste tipo de piso que os usuários circulam e permanecem em suas casas. As medidas foram efetuadas a 20m (M1 e M2) e $40 \mathrm{~m}$ (M3, M4 e M5) de distância do eixo perpendicular da linha.

Figura 3. Sistema de medição apoiado diretamente no pavimento de concreto do passeio público

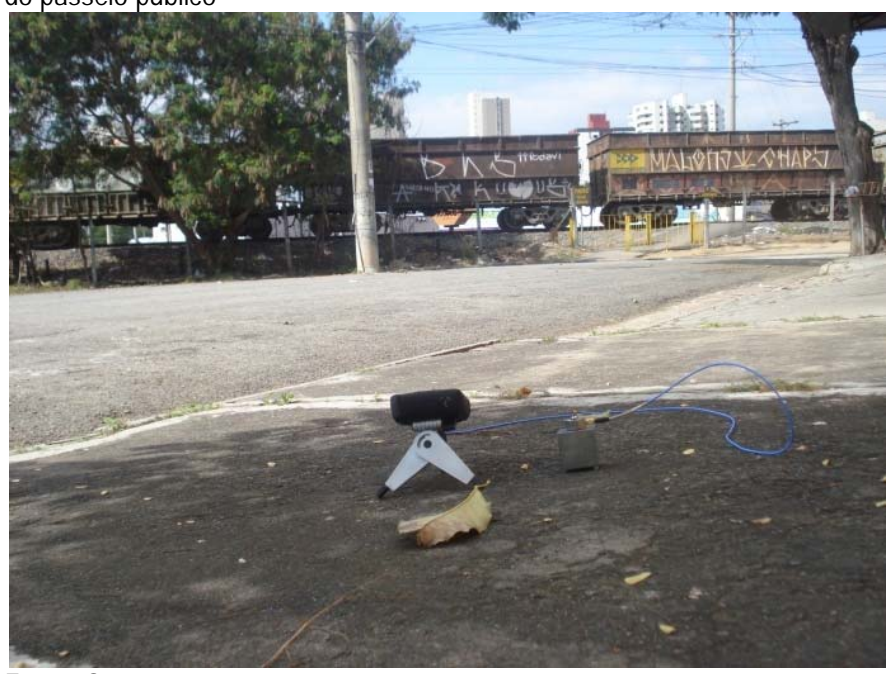

Fonte: Os autores

$\mathrm{Na}$ segunda avaliação o pod metálico foi apoiado diretamente no solo, Figura 4, para que fosse possível avaliar a PVP que incide sobre as edificações, sem a atenuação propiciada pelo piso asfáltico ou de concreto, sendo que as medidas foram realizadas a $5 \mathrm{~m}$ da linha (M6) e $10 \mathrm{~m}$ (M7).

A Figura 5 ilustra o local das medições sendo que a linha vermelha representa o traçado da linha férrea.

O critério da norma ISO 2631 (INTERNATIONAL ORGANIZATION FOR STANDARDIZATION, 1997), em valores globais, foi considerado para a avaliação de incomodidade. A área analisada apresenta características residenciais de maneira que a PVP limite é de 0,4 mm/s. O critério da norma na DIN 4150-3 (DEUTSCHES INSTITUT FUR NORMUNG, 1999), também em valores globais, foi considerado para avaliação da integridade estrutural das edificações. As edificações próximas à linha férrea são antigas, com mais de 40 anos, e não possuem uma estrutura de concreto armado ou aço, sendo as paredes responsáveis pela sustentação da cobertura. Dessa forma, a PVP limite considerada foi $8 \mathrm{~mm} / \mathrm{s}$.

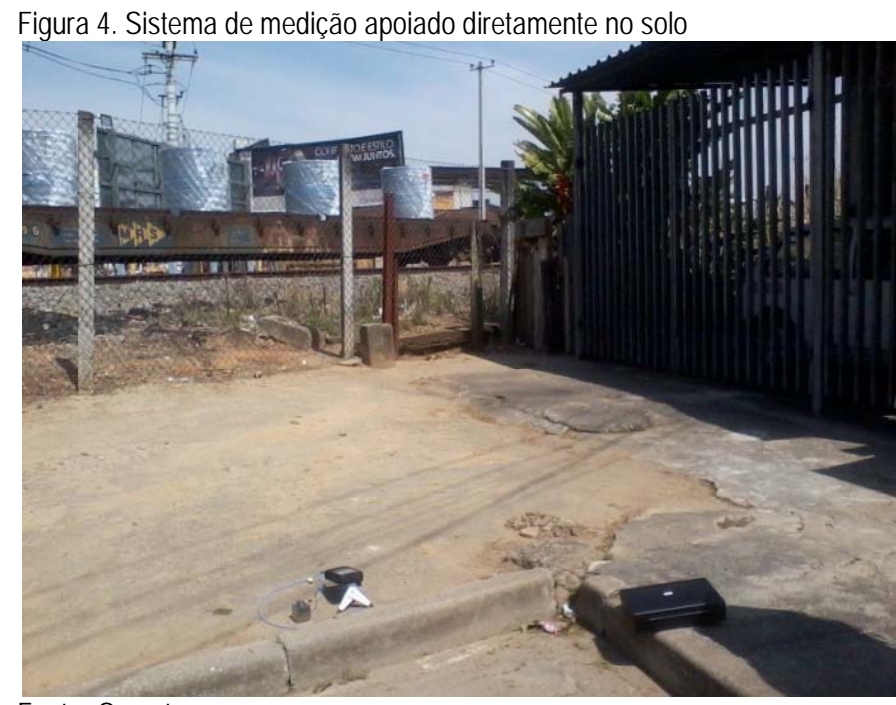

Fonte: Os autores

Figura 5.Vista dos pontos de medição e da linha férrea (em vermelho)

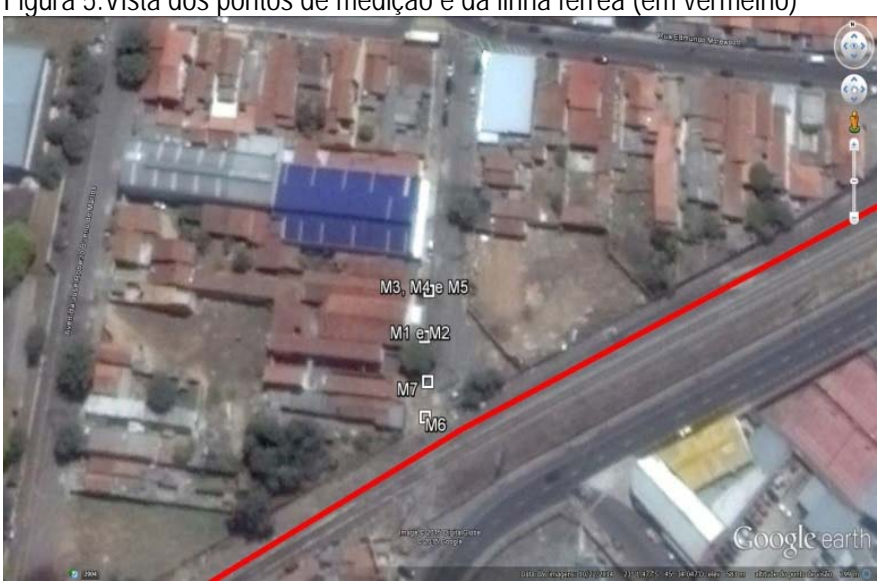

Fonte: Os autores

A Equação 1 foi utilizada para o cálculo do decaimento da energia vibratória com o aumento da distância. O valor de partida considerado $\left(w_{l}\right)$ foi o obtido por Brito (2014) para composições ferroviárias, $17,6 \mathrm{~mm} / \mathrm{s}$ a $4 \mathrm{~m}\left(r_{l}\right)$ de distância. O tipo de fonte considerada (n) foi a linear, já que a composição ferroviária é consideravelmente maior que as distâncias entre a fonte e o receptor. $\mathrm{O}$ fator de solo $(\alpha)$ adotado foi o de solos argilosos. 


\section{Resultado e Discussão}

A Figura 6 apresenta os valores obtidos sobre o pavimento asfáltico a $20 \mathrm{~m}$ da linha. $O$ critério de incomodidade da ISO 2631 (INTERNATIONAL ORGANIZATION FOR STANDARDIZATION, 1997) foi superado com folgada margem, sendo a PVP máxima de $2,42 \mathrm{~mm} / \mathrm{s}$. A Figura 7 apresenta os resultados obtidos a $40 \mathrm{~m}$ da linha sobre piso de concreto. Na M3, M4 e M5 o critério da ISO 2631 foi novamente superado. A PVP máxima obtida nas três medições foi de $1,20 \mathrm{~mm} / \mathrm{s}$. Desta forma, os resultados indicam que o critério de incomodidade é superado a uma distância superior a 40 $\mathrm{m}$ da linha, sendo portanto, o tráfego ferroviário fonte de incômodo a toda sua população lindeira.

Figura 6.Gráfico das PVPs obtidas a $20 \mathrm{~m}$ de distância da linha sobre pavimento asfáltico

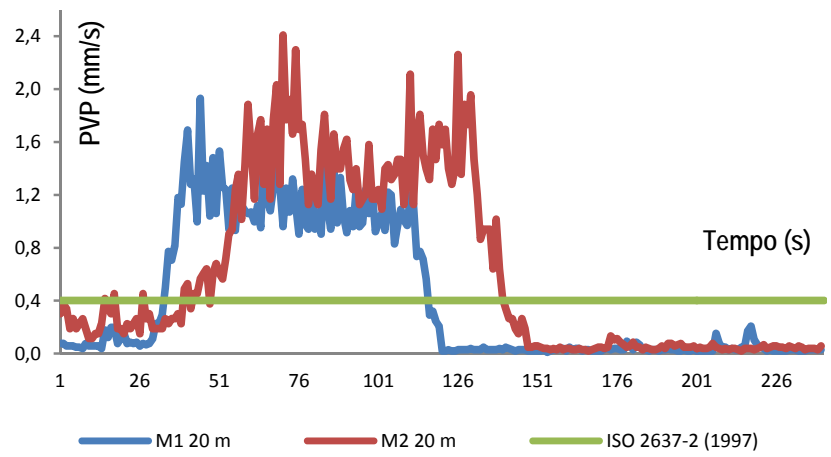

Fonte: Os autores

Figura 7.Gráfico das PVPs obtidas a $40 \mathrm{~m}$ de distância da linha sobre pavimento de concreto

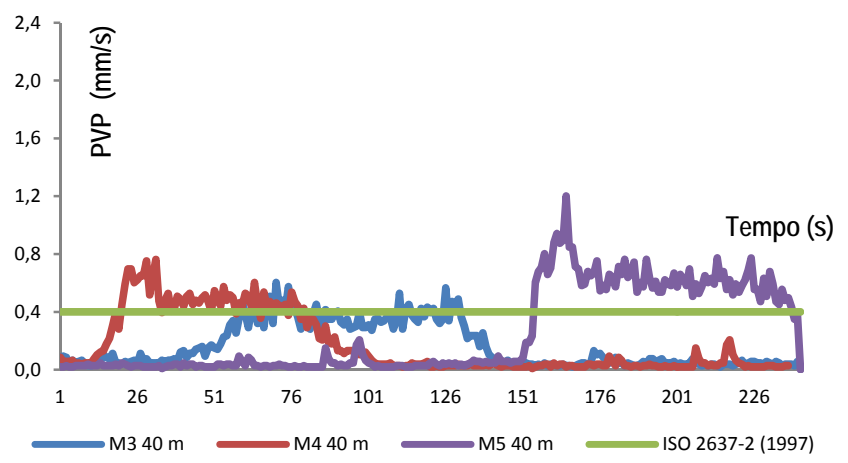

Fonte: Os autores

O estudo apresentado por Klaeboe et al. (2003) relaciona a velocidade de vibração em edificações e o potencial de reclamações da população. A Tabela 3 , baseada nesta pesquisa, apresenta a expectativa de percepção e motivação para reclamação em função dos resultados obtidos em cada ponto de medição. Em todas as situações analisadas o índice de percepção é superior a $60 \%$, sendo que apenas na M3 fica limítrofe. A expectativa de motivação para reclamação é inferior a
25\%. Deve-se destacar que este é um estudo realizado na Noruega onde os padrões de incomodidade da população são diferentes do Brasil.

Tabela 3 - Valores de PVP obtidos neste trabalho e as estimativas de percepção da vibração e a motivação à reclamação segundo (Klaeboe et al.,2003)

\begin{tabular}{cccc}
\hline Medição & $\begin{array}{c}\text { PVP } \\
\text { mm/s }\end{array}$ & $\begin{array}{c}\text { imativa de percepçãc Estimativa de chance de } \\
\text { vibração } \\
\text { (\%) }\end{array}$ & $\begin{array}{c}\text { motivação a reclamação } \\
\text { (\%) }\end{array}$ \\
\hline M1 & 1,93 & 75 & 21 \\
\hline M2 & 2,42 & 80 & 23 \\
\hline M3 & 0,62 & 58 & 10 \\
\hline M4 & 0,76 & 60 & 13 \\
\hline M5 & 1,20 & 70 & 18 \\
\hline
\end{tabular}

Fonte: Os autores

A Figura 8 apresenta os resultados obtidos em medições realizadas diretamente no solo a $5 \mathrm{~m}(\mathrm{M} 6)$ e $10 \mathrm{~m}$ (M7) de distância da linha. A $5 \mathrm{~m}$ de distância da linha a PVP obtida, $13,7 \mathrm{~mm} / \mathrm{s}$, supera com folgada margem o limite proposto pela norma DIN 4150-3 (DEUTSCHES INSTITUT FUR NORMUNG, 1999) para edificações em alvenaria em más condições de preservação, que é de $8 \mathrm{~mm} / \mathrm{s}$, e fica próxima ao limite para edificações em alvenaria em boas condições, que é de $15 \mathrm{~mm} / \mathrm{s}$. A uma distância de $15 \mathrm{~m}$ da linha a PVP foi de $5,82 \mathrm{~mm} / \mathrm{s}$, inferior ao limite proposto.

Figura 8. Gráfico das PVPs obtidas, diretamente sobre o solo, a 5 e $15 \mathrm{~m}$ de distância da linha

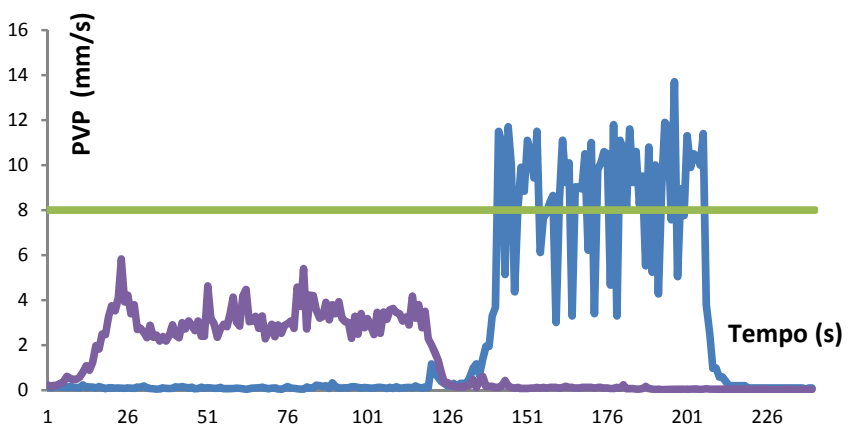

Fonte: Os autores

No local analisado foram constatados danos nas edificações a distâncias iguais e superiores a $10 \mathrm{~m}$, Figura 9, $30 \mathrm{~m}$, Figura 10 , e $50 \mathrm{~m}$ Figura $11 . \mathrm{Na}$ edificação localizada a $10 \mathrm{~m}$, a trinca pode ser classificada como de grande monta já que há uma viga de amarração danificada. $\mathrm{Na}$ edificação localizada a 30 $\mathrm{m}$, considera-se um dano de pequena monta, já que se trata de uma trinca na alvenaria. Na edificação localizada a 40 e $50 \mathrm{~m}$, considera-se um dano cosmético, já que se trata de uma fissura no reboco. Esta análise é embasada na classificação apresentada pela ISO 4866 (INTERNATIONAL ORGANIZATION FOR STANDARDIZATION, 2010). 
Figura 9.Vista de uma edificação localizada a $10 \mathrm{~m}$ da linha

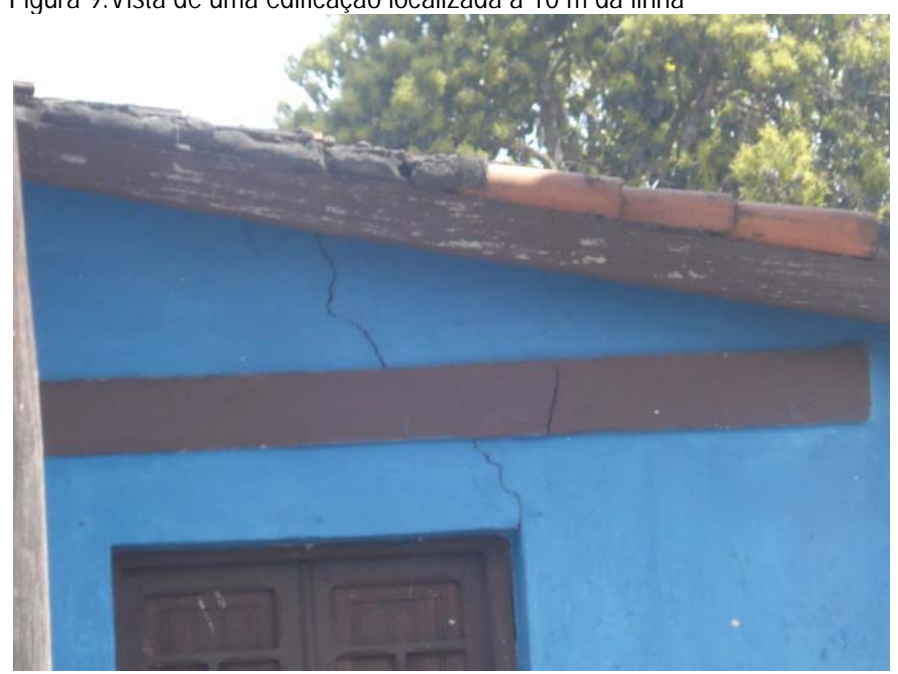

Fonte: Os autores

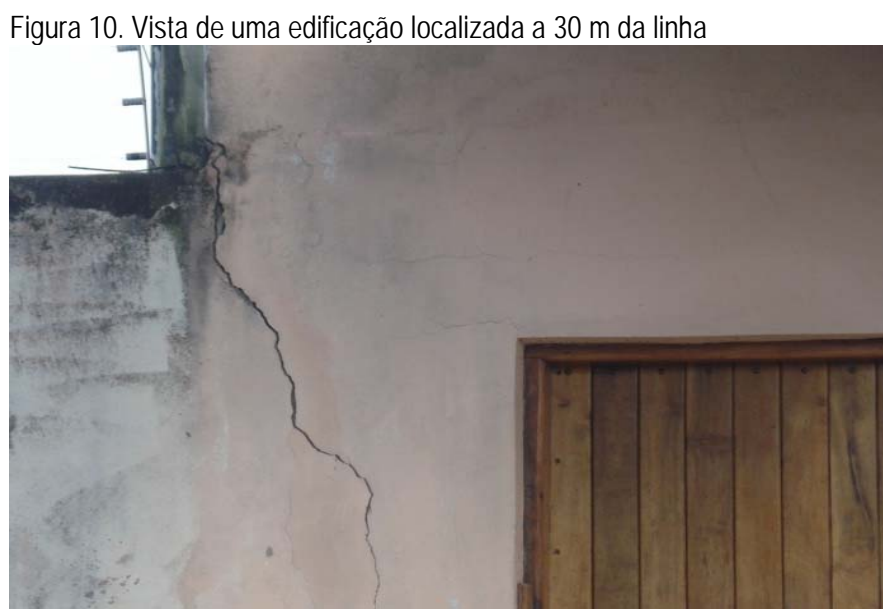

Fonte: Os autores

Figura 11. Vista interna de uma edificação localizada a $50 \mathrm{~m}$ da linha

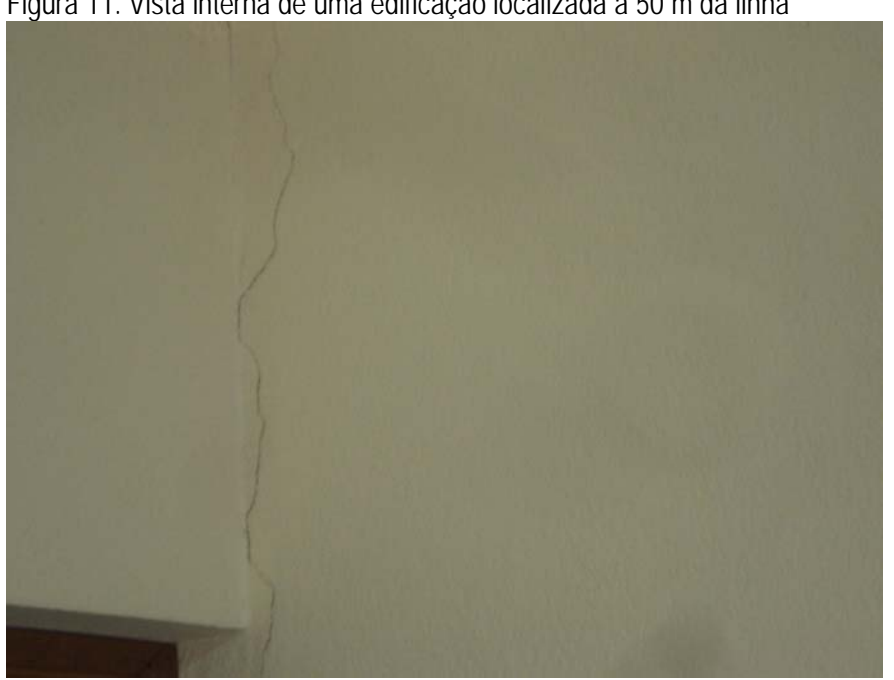

Fonte: Os autores

Outros fatores urbanos também podem causar danos semelhantes ao encontrado. Por exemplo, o tráfego rodoviário, que neste caso específico pode ser desconsiderado, já que a rua onde as edificações se encontram não tem saída, sendo voltada apenas para o tráfego local de pequeno porte. Além deste, o vazamento de água pode alterar a capacidade de suporte do solo e também ocasionar o recalque em fundações rasas, e consequentemente trincas e fissuras. Esta hipótese também pode ser desconsiderada, já que há uma distância razoável entre as edificações, de maneira que o vazamento deveria ser de grande porte para avariar todas simultaneamente, o que não poderia ficar despercebido por muito tempo. No local não há indícios de vazamentos no solo.

A Figura 12 ilustra o resultado gráfico do decaimento da PVP com aumento da distância calculado por meio da Equação 1. Os dados obtidos neste trabalho também são apresentados com uma boa correlação com a formulação teórica. Considerando esta modelagem, os critérios de danos estruturais com PVP de 8 e 15 mm/s, são obtidos a 7 e 4,5 m de distância da fonte respectivamente. Já o critério de incomodidade é obtido a cerca de $75 \mathrm{~m}$ de distância.

Figura 12. Gráfico da previsão do decaimento da PVP com o aumento da distância (Equação 1) comparado com os resultados obtidos neste trabalho

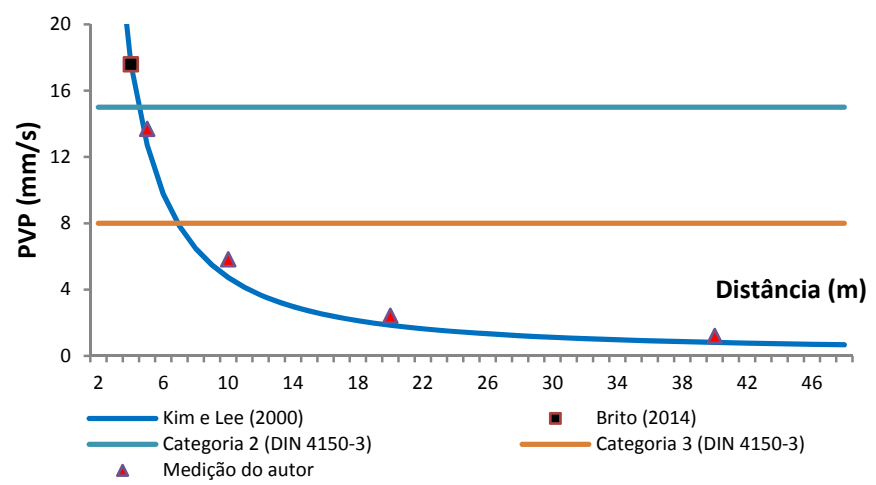

Fonte: Os autores

\section{Conclusão}

A vibração gerada pela passagem de composições ferroviárias no meio urbano pode ser considerada como fonte de incômodo á população já que a distâncias superiores a $40 \mathrm{~m}$ o critério internacional de incomodidade não é atendido e as faixas de domínio das linhas são consideravelmente inferiores a esta distância. De acordo com a formulação teórica essa distância deveria ser de pelo menos $75 \mathrm{~m}$.

A vibração gerada nas edificações mais próximas, entre 5 e $10 \mathrm{~m}$ de distância, também supera o critério internacional de danos estruturais. Os danos constatados nas edificações lindeiras à linha férrea em edificações a até $50 \mathrm{~m}$ de distância, demonstram que os limites internacionais não se adaptam a realidade construtiva nacional, e que as intempéries e má conservação do 
edifício potencializam o efeito da vibração nas edificações.

A formulação teórica utilizada apresenta uma boa correlação com os dados práticos podendo ser utilizada para criação de leis de zoneamento, determinação de afastamentos mínimos de residências e estudos das influências de novas linhas férreas.

A diferença entre os efeitos gerados por composições leves, pequenas e rápidas que circulam no meio urbano europeu, e as pesadas, grandes e lentas, que é o padrão nacional, também contribuem para que a normalização internacional não se adapte à realidade brasileira. Este fato indica à necessidade de um aprofundamento dos estudos dos efeitos da vibração na incomodidade das pessoas e nos danos causados nas edificações, com o intuito da formulação de uma normalização adaptada a realidade nacional. Deve-se destacar que é um fato recorrente no território nacional a passagem de linhas férreas de carga em áreas urbanas.

\section{Referências}

ASSOCIAÇÃO BRASILEIRA DE NORMAS TÉGNICAS. NBR 9653 - Guia para avaliação dos efeitos provocados pelo uso de explosivos nas minerações em áreas urbanas. Rio de Janeiro 2005.

ATHANASOPOULOS, G. A.; PELEKIS. P. C. Ground vibration from sheet pile driving in urban environment: measurements, analysis and effects on building and occupants. Soil and Dynamic and Earthquake Engineering, v. 19, n.5. pp 371-387, jul. 2000.http://dx.doi.org/10.1016/S0267-7261(00)00008-7

ATTEWELL, P. B.; SELBY, A. R.; UROMEIHY, A. Appraisal of ground vibration form civil engineering construction, International Journal of Mining and Geological Engineering. v. 7, pp 183-208, oct. 1989.

http://dx.doi.org/10.1007/BF00880942

ATTEWELL, P. B.; SELBY, A. R.; O'DONNELL, L. Estimation of ground vibration from driving piling based on statistical analyses of recorded data. Geotechnical and Geological Engineering, v. 10, n.1, pp 41-59, mar. 1992. http://dx.doi.org/10.1007/BF00881970

BACCI, D. L. C.; LANDIM, P. M. B.; ESTON, S. M.; IRAMINA, W. S. Principais normas e recomendações existentes para controle de vibrações provocadas pelo uso de explosivos em áreas urbanas, parte I. Revista Escola de Minas, v. 56, n. 1, jan./mar. 2003. http://dx.doi.org/10.1590/S0370-44672003000100010

BRITO, L. A. P. F. de. Avaliação da Vibração Gerada pelo Tráfego Rodoviário e Ferroviário no Hospital Universitário de Taubaté, In: ENCONTRO NACIONAL DO CONFORTO NO AMBIENTE CONSTRUÍDO. 11., 2011, Búzios.

Anais ... Buzio:UFRJ, 2011.

Vibração, Fonte de Incômodo à População e Danos às Edificações no Meio Urbano. Revista Ambiente Construído, v. 13, n.1, pp 120-141, jan./mar. 2013.

Avaliação das Principais Fontes de Vibração no Meio Urbano. Revista Ambiente Construído, v. 14, n. 4, pp. 233249, out./dez. 2014.

BRITISH STANDARD. BS 7385-1 Evaluation and measurement for vibration in building, Part 1: Guide for measurement of vibrations an evaluation of their effects on buildings. London 1990.

BS 7385-2 Evaluation and measurement for vibration in building, Part 2: Guide to damage levels from ground borne vibration. London 1993. 2009

BS 5228-2 Code of practice for noise and vibration control on construction and open sites-Vibration. London

COMPANHIA DE TECNOLOGIA DE SANEAMENTO AMBIENTAL. Decisão de Diretoria no 215/2007/E. São Paulo 2007.

DEUTSCHES INSTITUT FUR NORMUNG. DIN 4150-3, Vibration in buildings, effect in structures. Berlin 1999. 
FRANÇOIS, S.; PYL, L.; MASOUMI H. R.; DEGRANDE,G.. The influence of dynamic soil-structure interaction on traffic induced vibrations in buildings. Soil Dynamic and Earthquake Engineering, v. 27, n. 7, p. 655-674, jul. 2007. http://dx.doi.org/10.1016/j.soildyn.2006.11.008

GUPTA,S.; DEGRANDE,G.; LOMBAERT, G.. Experimental validation of a numerical model for subway induced vibrations. Journal of Sound and Vibration, v. 321, n3-5, pp 786-812, apr. 2009. http://dx.doi.org/10.1016/j.jsv.2008.10.014

INTERNATIONAL ORGANIZATION FOR STANDARDIZATION. ISO 2631-2 Mechanical vibration and shock -Evaluation of human exposure to whole-body vibration -- Part 2: Vibration in buildings (1 Hz to $80 \mathrm{~Hz}$ ). Geneva, 1997.

ISO 4866 Mechanical vibration and shock - Vibration of buildings - Guidelines for the measurement of vibration and evaluation of their effects on buildings. Geneva, 2010.

HUNAIDI, O.. Traffic vibrations in buildings. National Research Council of Canada, n. 39, June 2000.

KIM, D. S; LEE J. S.. Propagation and attenuation characteristics of various ground vibrations. Soil Dynamics and Earthquake Engineering. v. 19, n. 2, pp 115-126, feb. 2000. http://dx.doi.org/10.1016/S0267-7261(00)00002-6

KLAEBOE, R.; TURUNEN-RISE I.H.; HARVIK L.; MADSHUS C.. Vibration in dwellings from road and rail traffic Part II: exposure-effect relationships based on ordinal logistic regression models. Applied Acoustics, v. 64, n. 1, pp. 89109, jan. 2003. http://dx.doi.org/10.1016/S0003-682X(02)00053-1

${ }^{1}$ Luiz Antonio Perrone Ferreira de Brito

Engenheiro Civil. Doutor. Endereço postal: Rua Expedicionário Ernesto Pereira,225 Portão 1, Taubaté, SP, Brasil CEP 12020-330

\section{${ }^{2}$ Quésia Kamimura}

Economista. Doutora. Endereço postal: Rua Expedicionário Ernesto Pereira,225 Portão 1, Taubaté, SP, Brasil CEP 12020-330

\section{${ }^{3}$ Ademir Pereira dos Santos}

Arquiteto. Doutor. Endereço postal: Rua Expedicionário Ernesto Pereira,225 Portão 1, Taubaté, SP, Brasil CEP 12020-330 